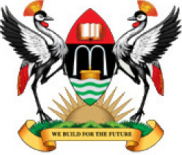

East African School of Higher Education Studies \& Development
Makerere Journal of Higher Education

ISSN: $1816-6822 ; 4(2)$ (2013) $311-326$

DOI: http://dx.doi.org/10.4314/majohe.v4i2.13

(C) The Author(s) 2013

Reprints \& permission: EASHESD

http://ajol.info/majohe

\title{
Implementation of Competency Based Teaching in Morogoro Teachers' Training College, Tanzania
}

\author{
Ayoub C Kafyulilo ${ }^{1, *}$, Innocent B Rugambuka ${ }^{1}$, Ikupa Moses ${ }^{1}$ \\ ${ }^{1}$ Dar es Salaam University College of Education [*Corresponding author: \\ vangidunda@yahoo.co.uk]
}

\begin{abstract}
The purpose of this study was to investigate the implementation of competency based teaching approaches in education in Morogoro Teachers' Training College Tanzania. A total of 78 pre-service teachers from Morogoro Teachers' Training College participated in the study. To draw an understanding of the extent to which pre-service teachers were well trained to implement competency based teaching approaches in their teaching, a questionnaire was administered to all 78 pre-service teachers, and 46 of them also participated in a structured interview. Results revealed that pre-service teachers perceived their understanding and ability to implement competency based teaching approaches as high, but during interviews it was revealed that they had difficulties in explaining some competency based concepts. Thus, it is concluded that, competency based teaching approaches are not well implemented in schools in Tanzania and more efforts need to be devoted in the development of tutors' and principals' understanding of competency based teaching approaches.
\end{abstract}

Keywords: Competency based approaches; Teacher training; Pedagogy.

\section{$1 \quad$ Introduction}

In 2005, Tanzania introduced competency based curriculums which led to the development of competency based learning and competency based assessment in secondary education (World Bank, 2011). In 2006, competency based curriculum was introduced in primary education as well (Woods, 2008). Since 2006 when competency-based curriculum became operational in both primary and secondary schools, there have been serious financial and human commitments to retrain and support teachers, head teachers and other education professionals to develop the necessary competence and confidence to effectively handle competency based education (Woods, 2008). The 
introduction of competency based curriculum is the second major pedagogical change in the country after the first change that took place in 1967, when education for self reliance was introduced. Competency based education involves some pedagogical changes in the curriculum and instructional approaches to incorporate outcome based learning rather than theoretical understanding of concepts (content based curriculum). In this paper we focus on the competency based teaching approaches that teachers are expected to develop from teacher training colleges in order to effectively implement the competency based curriculum in schools when they get employed.

\subsection{Background and Context of the Study}

Competency based education has most often been confused with the education for self reliance in Tanzania. However, the two terms are actually different in terms of their aims and composition. Education for Self-Reliance aimed at providing individuals with education that would make them self-reliant and play an active role in the community. It also aimed to prepare people to play a dynamic and constructive part in the development of the society and inculcating the sense of commitment to the total community (Nyerere, 1967). In the education for self reliance, students were prepared to develop various competencies related to the community needs and ability to fit well to the needs of the community and their future life. Although this philosophy was considered effective for the development of self-reliant individuals of the society, it did not last longer before it turned to content based learning approach which was inherited from the colonial regime.

On the other hand, competency based education has been described by Mrowicki (1986) as a component of essential skills, knowledge, attitudes, and behaviours required for effective performance of a real-world task or activity. However, Thinktwice (2007) defines competency based curriculum as a research-supported curriculum based on the primary goal of defining the critical behaviours needed for effective and superior individual and organizational performance. It focuses on observable and measurable behaviours which can be manifested through some underlying intents driven by a person's basic motivations, personality, attitude, values, or self-concept (Weddel, 2006; Thinktwice, 2007). Thus, competency based education is related to outcome based instruction and is adaptive to the changing needs of students, teachers, and the community (cf. Schneck, 1978). Competency based education addresses what the learners are expected to do rather than what they are expected to learn about (Weddel, 2006). In other words competence based education is a productive education which focuses on what an individual does with the education he claims to possess. The primary focus of competence 
based education is not possession of education but what one does in real life with the possessed education.

Sudsomboon, Anmanatarkul and Hemwat (2007) describe competency based education as the education that enables an individual to perform practically and measurably by using a set of knowledge and skills acquired through effective training. Sudsomboon et al (2007) identify seven elements in which a competency based education is realized:

- learners acquire experience and knowledge in their lives,

- curriculum designer provides an experience that will tap learners' values and ideas,

- learners experience new situations and match new experience with previous learning,

- learners distil new values and new knowledge;

- learners try out new behaviours and acquire new experiences and knowledge in both simulated and "real world" environments

- learners continue to process experience and knowledge as basis of original knowledge and experience and

- Learners apply new behaviours in "real world" environment" (Sudsomboon et al. 2007)

Looking at the mentioned elements, competency based education is considered to focus on the development of an entire individual, different from content based education which in most cases prioritizes on individuals' cognition. It is on this factor, among others, that a number of countries including Tanzania decided to change their national education curriculum from content based to competency based.

Woods (2008) describes the changes from content based curriculum to competency based curriculum as one of the most significant changes that took place in primary education (from 2006) and secondary education (from 2005) since the introduction of free primary education in Tanzania. In respect to the changes, the Ministry of Education and Culture- MoEC (2001), called upon education to be treated as a strategic agent for mindset transformation and for the creation of a well educated nation. The Ministry anticipated developing the education system that enables the Tanzanians to be sufficiently equipped with the knowledge needed to competently and competitively solve the development challenges which face the nation.

Based on Woods, the introduction of competency based curriculum in the education system of Tanzania shifts the orientation of the content, largely but not exclusively, away from the rote memorisation of factual knowledge to competency based learning which is largely instrumental. This focuses much more on the understanding of concepts, and the acquisition of skills and 
competencies, which in turn calls for changes in teaching, learning and assessment approaches (Woods, 2008; World Bank, 2011; Wangeleja, 2010).

The need for changes in the instructional approaches, calls for changes in the teacher training program to equip teachers (both in-service and pre-service) with the necessary competencies for handling the new teaching paradigm (cf. Woods, 2008). Teachers need to have considerable skills to match the curriculum to learners and thus, requiring modification in the curriculum of teacher training colleges and an intensive widespread in-service training for all those already teaching. According to Woods (2008) these changes, also necessitates a serious financial and human commitment to the retraining and support of teachers, head-teachers and other education professionals to ensure that they have the necessary competence and confidence to implement the pedagogical approach.

\subsection{Statement of the Problem}

Despite the fact that competency based curriculum is seven years young since its inception in secondary schools, there is no clear evidence of whether or not teachers are appropriately implementing competency based teaching approaches. A recent study done by HakiElimu on mass student failure in the National Examination found that the curriculum has always been poorly implemented because the majority of stakeholders did not aptly understand the requirements of the educational guidelines (Rweyemamu, 2012). On the other hand Woods (2007) points out that, although the Secondary Education Development Plan (SEDP) shows that teacher training is a priority and steps are required to provide for a well educated, professional and skilled teaching force, to date, much of the required interventions have not taken place. General preservice teacher training program has been uncoordinated, underfunded and poorly staffed (ibid.). Teachers' Resource Centres (TRC) have been established to provide in-service training, mentoring and peer support, but they are not well utilized. Although politicians, teachers and other education stakeholders in the country claim that Tanzania education system is competency based there is no evidence from research which indicates the extent of the implementation of this new teaching, learning and assessment approach to warrant these rhetoric statements. However, a number of studies (Alphonce, 2008; Mgalla \& Mbulanya, 2008; Komba \& Nkumbi, 2008; Woods, 2007,) have reported a serious shortage of well qualified and expert teachers competent to guide learners through the new competency based curriculum and learning styles, and the absence of an assessment and examination regime able to reinforce the new approaches and reward students for their ability to demonstrate what they know, understand and can do. 
To a large extent, teachers have continued teaching by using the traditional instructional approaches and assessments. Students have also continued learning through memorization rather than creating and inventing new ideas through inquiry learning approaches. It was thus, the intent of this study to investigate the extent to which competency based teaching approaches have been implemented in education in Tanzania. This was done through the investigation of the extent to which pre-service teachers are prepared to practice competency based teaching approaches in schools after graduation from teacher training colleges.

\subsection{Research Questions}

The major research question that guided the study was: what is the level of understanding of competency based teaching approaches among the preservice teachers at Morogoro Teacher Training College (TTC)? This question is divided into four sub-questions:

1. What do pre-service teachers at Morogoro TTC know about competency based teaching approaches?

2. To what extent are the pre-service teachers at Morogoro TTC prepared to implement competency based teaching approaches in schools?

3. To what extent can pre-service teachers at Morogoro TTC practice competency based classroom management and assessment?

4. What competency is indicated by the pre-service teachers in the preparation of a competency based lesson plan?

\section{$2 \quad$ Methodology}

\subsection{Participants}

Participants in this study were the second year science pre-service teachers from Morogoro Teacher Training College in Tanzania. A total of 78 pre-service teachers participated in filling up a questionnaire and 46 among the 78 also participated in a structured interview with the researchers. Participants were selected through a purposeful sampling technique and simple random sampling technique. In the purposeful sampling approach, only second year students were considered for the study. The study focused on the second year students because they were in their final year of studies thus, believed to have acquired the necessary knowledge and skills of applying competency based teaching approaches. In addition, second year students had already attended a three months Block Teaching Practice (BTP), which is sufficient for them to practice the learnt knowledge and competences. By working with the finalists it had an 
implication that the knowledge they would demonstrate during the study is the knowledge they were going to practice in the actual teaching as were about to graduate within a short time.

A simple random sampling approach involved a coin tossing to select one of the streams between science and art streams. A representative from the art stream chose a tail and the one from science stream chose a head. A first year student was asked to toss the coin on behalf of the second year student teachers in the two streams and the one who chose the head was the winner. Thus, all 78 second year science students who were available in the class were given the questionnaire to fill out. However, only 46 pre-service teachers turned up for the interview with the researcher the second day.

\subsection{Instruments}

There were two data collection instruments: the questionnaire and an interview guide. The questionnaire was administered to all teachers who participated in the study, where as the interview guide was used to carry out interviews with 46 pre-service teachers. Teachers to participate in the interview were randomly selected from amongst 78 pre-service teachers. The questionnaire adopted some of the questions from Schmidt et al (2009) and others from a competencies and assessment rubrics available at http://det.wa.edu.au/detcms/cmsservice/download/asset/?asset_id=7818716. Examples of questions adopted from Schmidt et al were those related to teachers' pedagogical knowledge and pedagogical content knowledge. Other questions were developed by the researcher to assess the level of pre-service teachers' understanding about competency based teaching approaches. In addition, there was one open ended question requiring every participant to prepare a competency based lesson plan. In order to provide them with a sufficient time for preparing the competency based lesson plan, pre-service teachers were given three day to fill up the questionnaire. The questionnaire had five points Likert scale, where $1=$ strongly disagree, 2 = disagree, $3=$ undecided, $4=$ agree, $5=$ strongly agree, and had a reliability of 0.95 Cronbach's Alpha. The interview guide was developed by the researchers to assess the pre-service teachers' general understanding of the competency based teaching approaches. The following two basic questions are among questions that were asked in the interview: (1) what do you know about competency based teaching approach? (2) What are the characteristics of competency based teaching approaches?

\subsection{Data Analysis}

Data from the questionnaire were analyzed by using IBM SPSS statistic version 20 , to compute means and standard deviations. The qualitative data from the 
interview were transcribed using express scribe and coded by using the codes that were generated from the study's findings (inductive coding). The coding schemes (Miles \& Huberman, 1994) were categorized as competency, competency based curriculum, competency based teaching approaches and characteristics of competency based teaching approaches. All interviews were coded by using Atlas-ti software version 6.2.

\section{$3 \quad$ Results}

Results for this study have been presented on the basis of the pre-service teachers' general knowledge of competency based teaching approaches, ability to implement competency based teaching approaches in their classrooms, ability to practice competency based assessments and classroom management as well as the ability to prepare a competency based lesson plan.

Findings have indicated that, majority of pre-service teachers believe to have sufficient knowledge of competency and competency based teaching approaches. However, during interview with pre-service teachers, majority of them were able to define a word competency but not able to describe a competency based curriculum and competency based teaching approaches. As it was for the general knowledge of competency based teaching approaches, pre-service teachers perceived their practices with competency based teaching approaches to be high. However, majority of them were not able to prepare a competency based lesson plan.

\subsection{General Knowledge about Competency-based Teaching}

Pre-service teachers perceived their general knowledge about competency based teaching approaches to be high, with means above average $(M>3.5)$. Their understanding about the concept "competency" was perceived the highest with a mean above 4 which indicates that majority of the pre-service teachers seem to know what was it (Table 1).

Table 1: General knowledge about competency based teaching approaches $(\mathrm{N}=78)$

\begin{tabular}{lll}
\hline Competencies & Mean & SD \\
\hline Competency refers to knowledge skills and attitudes & 4.26 & 0.780 \\
I know what are competency based teaching approaches & 3.92 & 1.003 \\
I can practice competency based teaching approaches & 3.94 & 1.049 \\
I know the characteristics of competency based teaching & 3.73 & 1.159 \\
I can plan a lesson that is competency based & 3.83 & 1.098 \\
I know how to engage students in competency based learning activities & 3.86 & 0.990 \\
\hline
\end{tabular}


Although data in Table 1 indicate a high level of the pre-service teachers' understanding of the competency based teaching approaches with means above average $(M>3.8)$, their standard deviations were moderately high. This may mean that there were some pre-service teachers who had limited knowledge of competency based teaching approaches.

Pre-service teachers were further assessed on their ability to practice various competency based instructional approaches. As was for the general knowledge, pre-service teachers perceived their ability to practice competency based instructional approaches to be high ( $M=4$ or above 4) (Table 2).

Table 2: Ability to practice competency based instructional approaches $(\mathrm{N}=78)$

\begin{tabular}{lrl}
\hline Instructional practices & MeanSD \\
\hline I can easily select a suitable teaching approach for a given subject topic & 4.28 & 0.662 \\
I can adapt my teaching based upon what students currently understand or $_{4}$ & 4.05 & 0.788 \\
do not understand & 4.24 & 0.607 \\
I can use teaching approaches that support learners creativity & 3.97 & 0.772 \\
I can use teaching approaches that facilitate higher order thinking & 4.13 & 0.691 \\
I can use teaching approaches that enable learners to solve their problems & & \\
I know the teaching approaches that can support students in learning & & 0.821 \\
complex concepts & 4.23 & 0.701 \\
\hline
\end{tabular}

As indicated in Table 2, majority of pre-service teachers believe to have a good understanding of the instructional practices which are competency based. However, the standard deviations were moderately large, which may imply that some of the pre-service teachers had limited knowledge of competency based instructional approaches.

Pre-service teachers also participated in a structured interview, where they were asked to define the word competency. Their responses were being noted as "correct definition", "somewhat close to the correct", "pointed out some components of competency", "provided a wrong definition", and "completely don't know". The last option was for those who declared right away that they do not know the definition of competency based (Figure 1). 


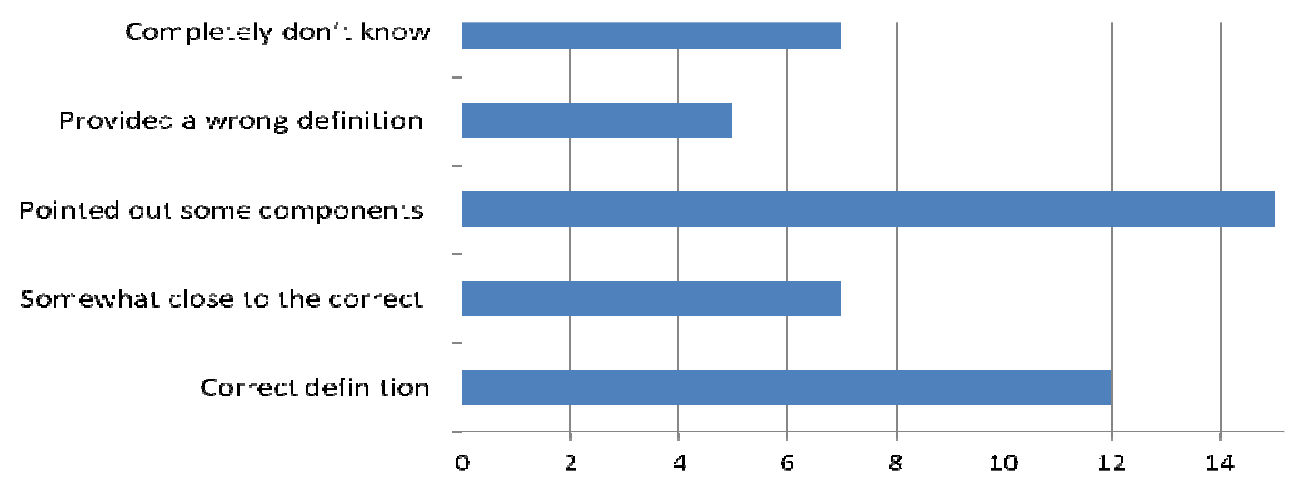

Figure 1: Pre-service teachers' ability to define competency $(\mathrm{N}=46)$

Findings in Figure 1, shows that a good number of pre-service teachers were able to point out some components of competency and some of them were completely unable to define the term competency. Results further indicated that, pre-service teachers' were not able to define competency based teaching approaches. Only few pre-service teacher were able to provide a correct definition of competency based teaching approaches (see Figure 2).

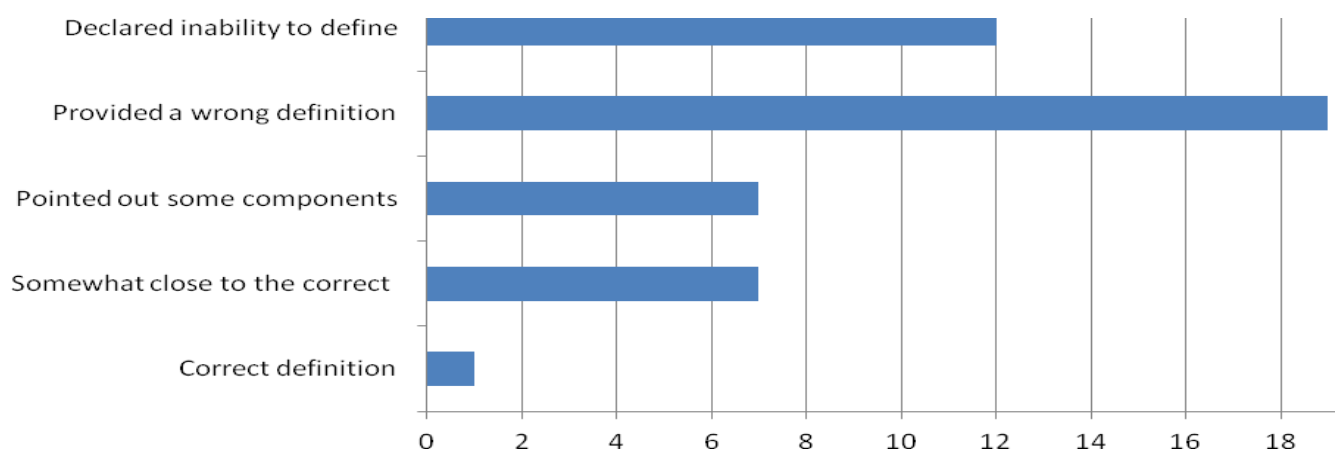

Figure 2: Ability to define competency based teaching approach $(\mathrm{N}=46)$

From Figure 2, it can be noted that majority of the pre-service teachers were not able to provide a correct definition of competency based teaching approaches and many others declared to have no idea about competency based teaching approaches.

\subsection{Knowledge of implementing competency based practices}

Pre-service teachers were also assessed for their knowledge of implementing competency based practices in teaching, assessment and management in various 
schools settings. Findings indicate that majority of pre-service teachers perceived their ability to implement competency based practices was above average $(\mathrm{M}>3.5)$ (Table 3).

Table 3: Practices with competency based approaches $(\mathrm{N}=78)$

Competency based practices

Mean SD

I can demonstrate classroom practice that is informed by current trend, research and $3.92 \quad 0.923$ system initiatives

I can develop, analyze and apply a repertoire of fair and inclusive assessment and $3.77 \quad 0.979$ reporting strategies that are sensitive to individual learning needs

I can provide a range of planned and meaningful opportunities for students to 3.860 .801

demonstrate progress, autonomous and consistent achievement of outcomes using

valid and reliable assessment methodology

I can negotiate explicitly criteria with students for assessment based on intended $3.97 \quad 0.805$

learning outcomes and provide formative information to enhance students' reflection

I can provide comprehensive information on timely and ongoing basis using formal $3.91 \quad 0.885$

and informal methods to report to parents, students and other stakeholders on students'

achievement and progress in relation to outcomes

I can engage in ongoing critical reflection to generate and apply new ideas that $4.03 \quad 0.925$ contribute to improvement in my teaching and leadership practices

Findings in Table 3 indicate that majority of pre-service teachers perceive their knowledge of implementing competency based practices was high. However, as was the case for other aspects of competency based approaches; the standard deviations are slightly high, indicating some disagreement between respondents.

\subsection{Assessing and management of a competency based classroom}

Pre-service teachers were also asked to present their perceived knowledge of providing a vivid assessment and management of a competency based classroom. As was the case for other components, general knowledge and competency based practices, pre-service teachers perceived their knowledge to be high with a mean above average $(M>4)$ (Table 4).

Table 4: Assessment and management of a competency based classroom $(\mathrm{N}=78)$.

\begin{tabular}{lll}
\hline Knowledge of assessing and managing a competency based classroom & Mean & SD \\
\hline I know how to assess students performance in a classroom & 4.29 & 0.705 \\
I can collaborate with other teachers to provided a well moderated and balanced & 4.12 & 0.789 \\
judgement on evidence collected over time and in a range of contexts & 4.15 & 0.823 \\
I can assess students learning in multiple ways & 4.19 & 0.646 \\
I can use wide range of approaches for evaluating students progress & 4.18 & 0.785 \\
I know a lot of different approaches of solving students learning problems & 4.21 & 0.727 \\
I can adapt different classroom management approaches to different learners & 3.86 & 0.833 \\
I am familiar with common students understandings and misconceptions and how to & 4.40 & 0.671 \\
handle them & 4.37 & 0.584 \\
\hline I know how to manage the class when I teach
\end{tabular}


Although pre-service teachers indicated high level of understanding of the implementation of competency based practices including assessment and classroom management, majority of them were not able to describe the characteristics of the competency based teaching approaches (Figure 3).

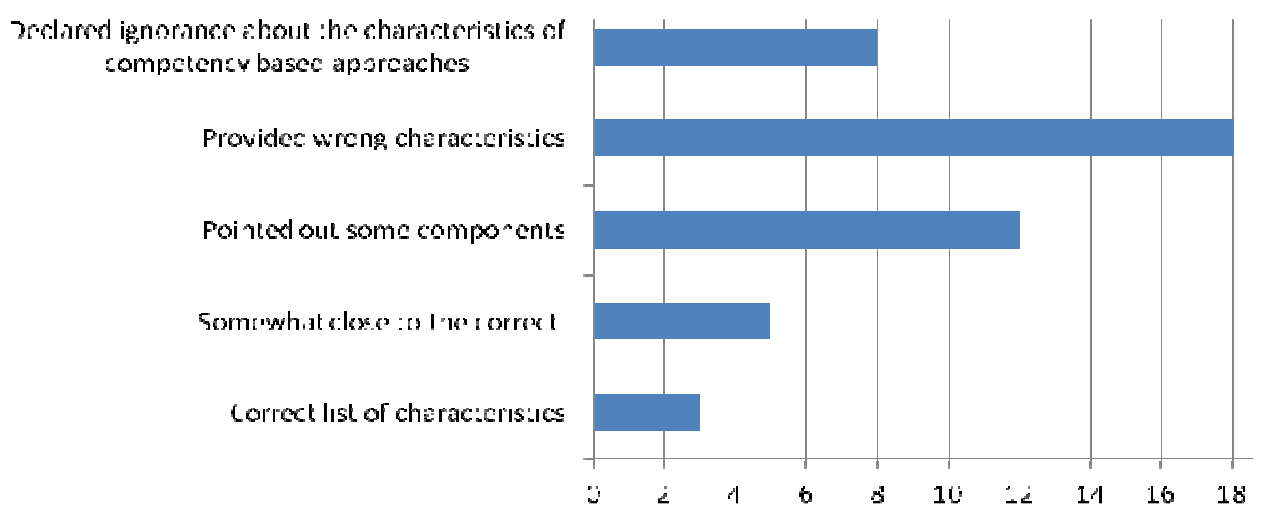

Figure 3: Ability to describe characteristics of competency based approaches $(\mathrm{N}=46)$

Figure 3 presents the pre-service teachers' responses when they were asked to mention at least one of the characteristics/features of competency based teaching approaches. Majority of them were not able to provide the correct characteristics of competency based teaching approaches. Instead, they ended up listing only the components of the competency based teaching approaches.

\subsection{Lesson Plan Preparation}

At the end of the questionnaire, there was an open question that required all pre-service teachers to prepare a competency based lesson plan for any subject of their interest. Assessments were made on the basis of a proper statement of competency based objectives, proper statement of teachers' activities, proper statement of the students' activities and the students' assessment plans. Findings showed, that majority of the pre-service teachers were able to properly state the competency based objective, but not able to properly state the teachers' activities, students' activities and assessment plans (Figure 4).

From the findings presented in Figure 4, a good number of the pre-service teachers were able to state competency based objectives. About $19.2 \%$ of the pre-service teachers did not write a lesson plan despite the ample time (three days) they were given to work on the four pages questionnaire, including the lesson plan preparation. It was not immediately confirmed if the failure to write a lesson plan was caused by their limited knowledge of writing a competency based lesson plan or they did not want to respond to the question. 


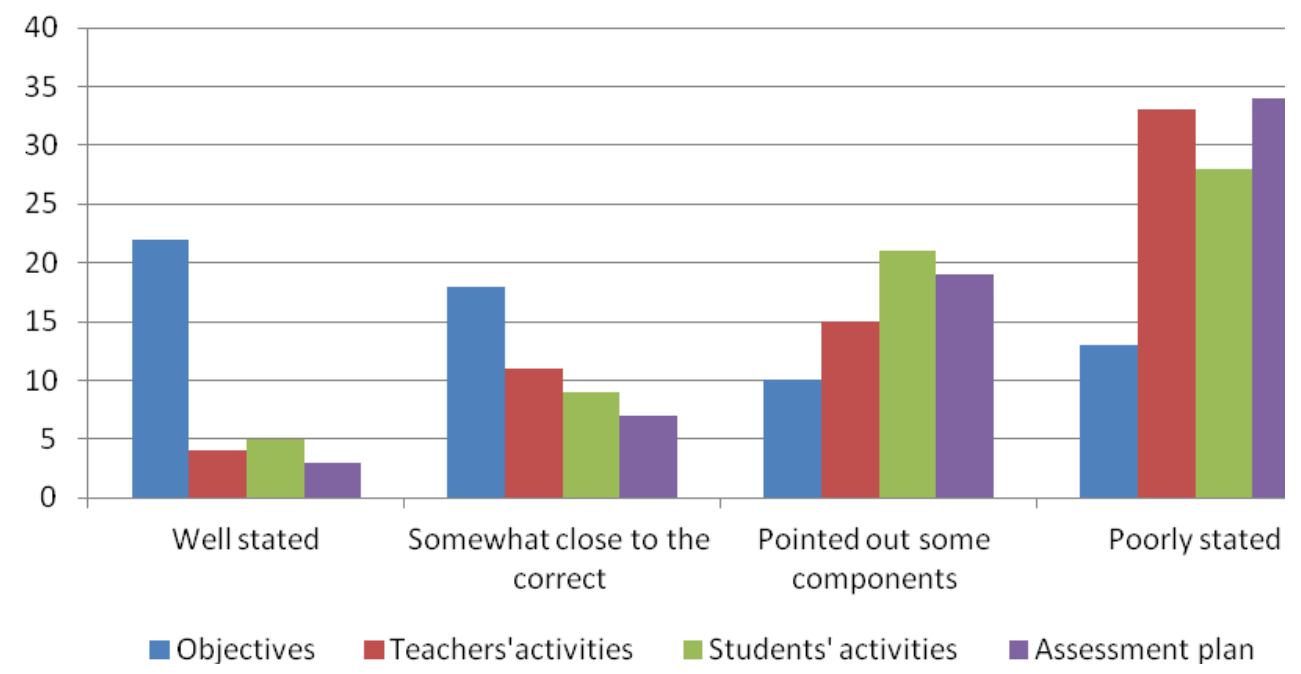

Figure 4: Pre-service teachers' ability to prepare a competency based lesson plan

\section{$4 \quad$ Discussion and Conclusion}

The purpose of this study was to assess the extent to which competency based curriculum is implemented in education in Tanzania. The study particularly focused on the assessments of the implementation of the competency based teaching approaches. Mostly assessed were the competency based teaching practices as applied in competency based approaches. Findings of the study suggest that, pre-service teachers theoretically know about competency based approaches but have limited ability to demonstrate it.

While in the questionnaire (self reported survey), pre-service teachers perceive their knowledge about competency based teaching approaches, practices and assessments to be high; in the interview some of the pre-service teachers, were not able even to define the term competency. Overall, the findings from the questionnaire were almost disapproved by interview findings. In this study the findings of the interview are considered to be highly informing the reality of the pre-service teachers' capability with the competency based teaching approaches because interview questions required the pre-service teachers to provide evidences of their understanding about competency. According to Albanese et al (2008), competency can be evaluated through the demonstrable abilities of the student. As per their responses in interview, preservice teachers had limited knowledge of the competency based curriculum and teaching approaches. Their inability to apply competency based approaches is further confirmed through the lesson plan preparation; where majority of the 
pre-service teachers were only able to state the competency based objectives but not the competency based learning activities.

The findings in this study are further informing that pre-service teachers need a kind of practices with the competency based teaching approaches in order to be able to effectively implement the approaches in their teaching. Albanese et al. (2008) argue that, when we want an individual to be competent, we need to consider three elements which are; what an individual is able to do, how he approaches his practice and how he acts as a professional. Since the studied pre-service teachers were in their last year of studies and had already participated in the field work, it was expected that they would demonstrate ability in the preparation of a competency based lesson plan and demonstrate an understanding of the competency based practices and their characteristics. In contrast, pre-service teachers were not able to properly demonstrate these competencies. These findings may imply that, pre-service teachers graduating from Morogoro teacher training college have limited knowledge and skills of applying competency based approaches in their teaching. However, since Tanzania follows a centralized system of education, where all schools and teacher training colleges at certificate and diploma levels follow the same curriculum, it may not be surprising that all pre-service teachers graduating from all teacher training colleges in the country have the same level of understanding about competency based teaching approaches.

It might also not be amazing to find that all teacher training colleges in Tanzania are producing graduates who believe that they know what competency based approaches are, but they actually don't know how competency based approaches are applied in practice. This conception is also reported by HakiElimu in Rweyemamu (2012) who argues that, competence based curriculum stakeholders including teachers do not aptly understand the curriculum in focus. They think they know it but they actually don't know how it is practiced. The missing link between what pre-service teachers think they know and what they can do in practices is likely to be resulting from the lack of training on competency based practices among college tutors. It is not objected that since 2006, when competency based education was introduced in the education system of Tanzania, little efforts were made by the Tanzanian government through the Institute of Education to train tutors and principals about competency based approaches. This suggests that tutors are likely to have just a superficial knowledge of competency based teaching approaches and thus being unable to mentor their student-teachers to develop competency based teaching approaches.

The findings from this study are suggesting that teachers were not well oriented to the practices of competency based teaching approaches, rather, they got a surface knowledge of what a competency and competency based approach is (Sudsomboon et al, 2007). Findings in Kafyulilo (2012) indicate that teachers 
were continuing to use the normal lecture methods even after having trained about the competency based approaches. This can be evidence that pre-service teachers are theoretically taught about competency based approaches and how it works but they don't practice it. This is confirmed through their limited ability to state the students' and teachers' activities in a lesson plan also limited ability to explain the characteristics of competency based teaching approaches. If preservice teachers were practicing competency based teaching approaches, they could easily list down the characteristics and also describe teachers' and students' activities in the competency based lesson plan. One may not hesitate to point out that the teacher education programme has failed to inculcate the practical training in pre-service teachers in a competency based manner.

The findings in this study have indicated that pre-service teachers have learned about competency, competency based curriculum, competency based teaching approaches and the preparation of a competency based lesson plan. Having learned these, pre-service teachers perceive their knowledge on competency based approaches to be high and sufficient for them to apply in the teaching field. However, when subjected to questions that require them to elaborate what they know about competency based practices, majority of them were only able to explain correctly about "competency" but unable to explain the competency based teaching approaches, state the characteristics of a competency based teaching approach or prepare a lesson plan that is competency based.

These findings hold our conclusion that competency based teaching approaches are not well implemented in teacher training colleges in Tanzania. And in the same veins, we consider that if pre-service teachers who graduate from teacher training colleges do not acquire sufficient and applicable knowledge about competency based approaches, it would be a sheer dream to expect them to apply the approaches in their teaching. This hypothesis takes us further to a conclusion that competency based teaching approach is still superficially implemented in education in Tanzania, and that, it may not be surprising if at the extreme, one argues that competency based curriculum in Tanzania is rather rhetoric than practical.

\section{References}

Albanese, M., Mejicano, G., Mullan, P., Kokotaili, P., \& Gruppen, L. (2008). Defining characteristics of educational competencies, Medical Education, (42), 248-255.

Alphonce, C.R. (2008). Mathematics teachers training in Tanzania, challenges and experiences. Dar es Salaam: University of Dar es Salaam. 
Kafyulilo, A. (2012). The relevance of authentic learning activities in developing competency and confidence of integrating technology in teaching among pre-service teachers in Tanzania. The African Symposium: An online journal of the African Educational Research Network, 12 (1), 99-109.

Komba, L. W., \& Nkumbi, E. (2008). Teacher Professional Development in Tanzania: Perceptions and Practices. A Journal of International Cooperation in Education, 11(3), 67 -83

Mgalla, Z. and Mbulanya G. (2008). Mobile teaching in Tanzania: a solution or a saddle? Netherlands Development Association. Retrieved on $12^{\text {th }}$ July 2012 from

http://www.snvworld.org/sites/www.snvworld.org/files/publications/tanzania _-_mobile_teaching_a_solution_or_a_saddle.pdf

Miles, M. B., \& Huberman, A.M. (1994). Qualitative data analysis. London: SAGE Publication.

Mrowicki, L. (1986). Project work English competency-based curriculum. Portland, OR: Northwest Educational Cooperative. Page 144 - Approaches and Methods in Language Teaching.

No author. (nd.). Competencies and assessment rubrics. Retrieved on $12^{\text {th }} \mathrm{July}$. 2012 from http://det.wa.edu.au/detcms/cmsservice/download/asset/?asset_id=7818716.

Nyerere, J. K., (1967). Education for Self-Reliance. In J. K. Nyerere Freedom and Socialism. Uhuru na Ujamaa. A selection from writings and speeches 1965-1967. Dar-es-Salaam: Oxford University Press.

Rweyemamu, A. (2012, November 23). Poor delivery of curricula, not faulty exams, explains failures. IPPMedia. Retrieved on $23^{\text {rd }}$ November 2012 from http://www.ippmedia.com/frontend/index.php?l=48327

Schneck, E.A. 1978. A guide to identifying high school graduation competencies. Portland: Northwest Regional Educational Laboratory.

Schmidt, D., Baran, E., Thompson, A., Koehler, M.J., Mishra, P., \& Shin, T. (2009, March). Examining pre-service teachers' development of technological pedagogical content knowledge in an introductory instructional technology course. In I. Gibson et al. (Eds.), Proceedings of Society for Information Technology \& Teacher Education International Conference 2009 (pp. 4145-4151). Chesapeake, VA: AACE.

Sudsomboon. W, Anmanatarkul, A. Hemwat, B. (2007) development of a competency-based instruction on automotive suspension system subject. A paper presented at ERES 20, 5th international conference on developing real-life learning experiences: education reform through educational standards. Retrieved on 18 July 2012 from http://www.kmutt.ac.th/rippc/pdf/abs50/503002.pdf

Thinktwice. (2007). Using a Competency-Based Approach: Linking core competencies to your business strategy. Retrieved on $1^{\text {st }}$ July, 2012 from 
http://www.thinkwiseinc.com/Files/Competency-Based-ApproachWhitePaper.pdf

Wangeleja, M.J.N. (2010). The teaching and learning of competence based mathematics curriculum: methods and techniques: A paper presented at the annual seminar of the Mathematical Association of Tanzania at Mazimbu campus, Sokoine University of Agriculture. Morogoro13-18/9/2010.

Weddel, K. S. (2006). Competency based education and content standards. Northern Colorado Literacy Resource Centre. Retrieved on $1^{\text {st }}$ July, 2012 from

http://www.cde.state.co.us/cdeadult/download/pdf/CompetencyBasedEducati on.pdf.

Woods, E. (2008). Tanzania case study. In UNESCO, country profile commissioned for the EFA global monitoring report 2008: Education for all by 2015 , will we make it? Paris: UNESCO.

World Bank. (2011). A regional exploration of pathways toward harmonization of mathematics \& science curriculum in the East African Community; Discussion Paper, Washington D.C: World Bank. 
